University of Massachusetts Amherst

ScholarWorks@UMass Amherst

Masters Theses 1911 - February 2014

1992

\title{
Therapists' attitudes about addressing the role of exercise in psychotherapy.
}

Derek J. Mcentee

University of Massachusetts Amherst

Follow this and additional works at: https://scholarworks.umass.edu/theses

Mcentee, Derek J., "Therapists' attitudes about addressing the role of exercise in psychotherapy." (1992).

Masters Theses 1911 - February 2014. 2215.

Retrieved from https://scholarworks.umass.edu/theses/2215

This thesis is brought to you for free and open access by ScholarWorks@UMass Amherst. It has been accepted for inclusion in Masters Theses 1911 - February 2014 by an authorized administrator of ScholarWorks@UMass Amherst. For more information, please contact scholarworks@library.umass.edu. 

4 (n) $\therefore \quad$ N

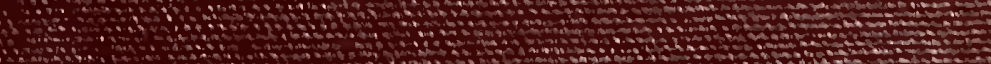

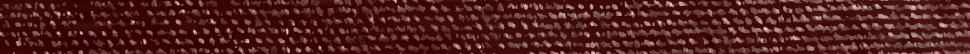
and

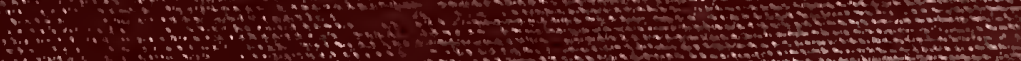
$\therefore$ 10

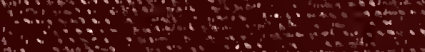


THERAPISTS' ATTITUDES ABOUT ADDRESSING THE ROLE OF EXERCISE IN PSYCHOTHERAPY

\title{
A Thesis Presented
}

\author{
by
}

DEREK J. MCENTEE

\author{
Submitted to the Graduate School of the \\ University of Massachusetts in partial fulfillment \\ of the requirements for the degree of \\ MASTER OF SCIENCE \\ May 1992 \\ Department of Psychology
}


THERAPISTS' ATTITUDES ABOUT ADDRESSING THE ROLE OF EXERCISE IN PSYCHOTHERAPY

A Thesis Presented

by

DEREK J. MCENTEE

Approved as to style and content by:

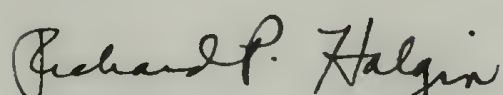

Richard P. Halgen, Chair

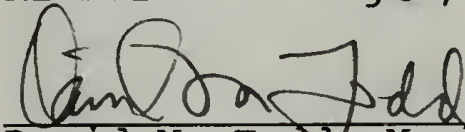

David M. Toda, Member

Romielanoff-Bulman Ronnie Janott-Bulman, Member 


\section{ACKNOWLEDGMENTS}

First, I would like to thank Richard Halgin, my committee chairperson, advisor, and friend, whose consistent support and encouragement made this project possible and manageable. I would also like to thank the members of my committee, David Todd, and Ronnie JanoffBulman, for their helpful suggestions at various stages of the study.

Thanks are also due to the interviewee subjects, Andrea Cole, Jeffrey Lukens, Marian MacDonald, and Peter Spencer, who took time out from their busy schedules to allow me to interview them. Their assistance in data analysis and offering in-depth case information provided depth and richness to the thesis.

Finally, and most importantly, I would like to express my sincere appreciation to my wife, whose support and tolerance allowed the successful and timely completion of this project. 


\section{ABSTRACT \\ THERAPISTS' ATTITUDES ABOUT ADDRESSING THE ROLE OF EXERCISE IN PSYCHOTHERAPY MAY, 1992}

DEREK J. MCENTEE, B.S., UNIVERSITY OF MASSACHUSETTS M.S., UNIVERSITY OF MASSACHUSETTS Directed by: Professor Richard P. Halgin A questionnaire was mailed to 250 psychotherapists selected from the National Register of Health Providers in Psychology to assess attitudes regarding the discussion of exercise in psychotherapy. Responses were received from 110 (44\%) of this group. Four senior level therapists were interviewed regarding the same topic. This study focused on (1) reasons therapists do or do not address exercise in therapy; (2) beliefs about the efficacy of exercise; (3) the relationship between orientation and the likelihood of discussing exercise, and (4) the relationship between gender and the likelihood of discussing exercise. Results indicate that exercising therapists are more likely to raise the issue and discuss exercise with their clients. In addition, male therapists are more likely to discuss exercise with their male clients than their female clients. Although cognitive-behavioral therapists are more likely than psychodynamic therapists to use a cognitive-behavioral approach, no relationship was found between exercise variables and primary orientation. 
TABLE OF CONTENTS

Page

ACKNOWLEDGMENTS iii

ABSTRACT . . . . . . . . . . . . . . iv

LIST OF TABLES . . . . . . . . . . . . . vii Chapter

1. INTRODUCTION . . . . . . . . . . . . . 1

An Operational Definition of Exercise . . . . 5

Exercise and Psychotherapy . . . . . . . . . 6

Purpose of the Study ............ 10

2. METHOD . . . . . . . . . . . . . 12

Subjects . . . . . . . . . . . . 12

Survey Respondents . . . . . . . . . 12

Interviewees . . . . . . . . . . . . 13

Instrument . . . . . . . . . . . . . . . . . 14

Procedure ................ 15

Step 1: Clinically Informing the Issue . 16

Step 2: Questionnaire ...... . . . 17

Step 3: Personal Interviews . . . . . . 18

3. RESULTS AND DISCUSSION . . . . . . . . . 19

Overview of Subject Attitudes . . . . . . . 19

Types of Exercise... . . . . . . . 20

Therapist Age Differences . . . . . . . 23

Reasons Why Exercise Would be Discussed . . . 24

Symptomatic Benefits . . . . . . . 24

Enhancement of the Therapeutic

Relationship . . . . . . . . . 27

Client Sense of Mastery . . . . . . . 28

Social Benefits... . . . . . . . . 30

Body Benefits... . . . . . . . . . . 31

Therapy Context . . . . . . . . . . . 32 
Reasons Why Exercise Would Not be Discussed . . 33 Perceived Inappropriateness . . . . . . 33 Confusion of the Therapeutic

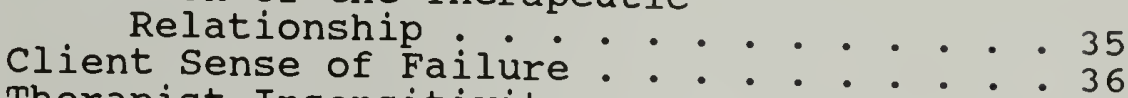
Therapist Insensitivity . . . . : : : : 37 Client Resistance . . . . . . . . . . 38 Therapist Unfamiliarity . . . . . . . : . 39 Eating Disorders . . . . . . . . . . . : . 40 Other Reasons . . . . . . . . . . . . 41

Efficacy Belief Differences ........ . . 43

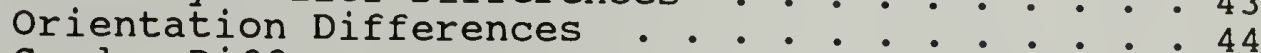
Gender Differences . . . . . . . . . . . : 47

4. CONCLUSIONS . . . . . . . . . . . 52

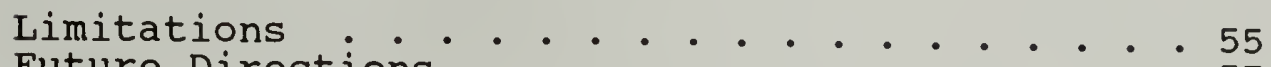

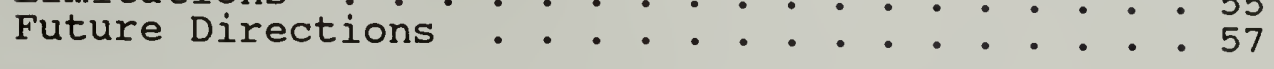
APPENDICES . . . . . . . . . . . . . . 58

A. SAMPLE COVER LETTER . . . . . . . . . . . 59

B. QUESTIONNAIRE ............... 60 BIBLIOGRAPHY . . . . . . . . . . . . . 63 


\section{LIST OF TABLES}

Table

1. Types of Exercise Engaged in

by Psychotherapists . . . . . . 22

2. Reasons Therapists Do or Do

Not Discuss Exercise with

Clients . . . . . . . . . 25 
Consistently positive findings have emerged in the literature regarding the psychological benefits of good physical health. More and more attention has been given to the relationship between fitness and mental health since health consciousness and exercise began possessing our society approximately fifteen years ago. The idea that exercise not only improves appearance, but can also attenuate depression and anxiety while enhancing self-concept, has helped carry the fitness and health craze into the 1990's. Countless numbers of people rely on exercise as a means of maintaining a wealth of both physical and psychological benefits (Plante \& Rodin, 1990), yet there has been controversy regarding this issue as various researchers have sought to either substantiate or disprove beliefs about the potentially beneficial effects of exercise during the past few decades. Overall, more than 1,000 articles have been published in scientific journals on the psychological effects of physical health, fitness and exercise (Hughes, 1984), with better than 200 surfacing in the past ten years alone. 
Most of the attention in the literature has been given to the relationship between exercise and the reduction of anxiety. In general, researchers have reported impressive results regarding the effects of both short-term and long-term exercise on state anxiety (Bahrke \& Morgan, 1978; Blumenthal, Williams, Needels, \& Wallace, 1982; Folkins, 1976; Holmes \& Roth, 1988; Lichtman \& Poser, 1983; Lobitz, Brammell, Stoll, \& Niccoll, 1983; Morgan, 1979; Raglin \& Morgan, 1987). Results regarding the effects of exercise on trait anxiety have been somewhat less consistent, yet still yield positive findings (Blumenthal et al., 1982; Pauly, Palmer, Wright, \& Pfeiffer, 1982; Schwartz, Davidson, \& Coleman, 1978).

The strongest evidence for the benefits of physical exercise on psychological functioning has emerged from work with sufferers of mild to moderate depression (Taylor, Sallis, \& Needle, 1985). The antidepressant effects of exercise are widely accepted, and several studies have demonstrated these benefits (Doyne, Chambless, \& Beutler, 1983; Fremont \& Craighead, 1987; Greist et al., 1978; Greist et al., 1979; Kavanaugh, Shepherd, Tuck, \& Qureshi, 1977; Klein et al., 1985; Lobstein, Mosbacher, \& Ismail, 1983). 
The third major area of investigation into the relationship between physical and psychological functioning has been in the area of personality, though this research has been inconclusive. Although it appears that there is no evidence that regular exercise has beneficial effects on personality in general, research has illustrated the relationship between physical fitness and self-concept variables (Ben-Shlomo \& Short, 1983; Dishman, 1986; Folkins, Lynch, \& Gardner, 1972; Sonstroem, 1984). Furthermore, decreases in anxiety as well as improvements in mood and self-esteem have been found through the therapeutic intervention of running (Boutcher \& Landers, 1988; Greist et al., 1979; Muller \& Armstrong, 1975; Orwin, 1974; Sachs, 1982; Trujillo, 1983).

Several authors have taken a closer look at the empirical data through comprehensive literature reviews. Scott (1960) and Layman (1974) compiled reviews about the relationship between physical activity and psychological variables of self-concept, mood, and body-image. Folkins \& Sime (1981) conducted a comprehensive review of articles pertaining to physical fitness training and psychological functioning among both normal and clinical populations; they concluded that exercise leads to improved mood and cognitive 
functioning during and after exercise, and that aside from self-concept, which increased with exercise, personality factors were unaffected by improvements in physical fitness. In another review, Taylor, Sallis, and Needle (1985) concluded that physical activity: (a) appears to alleviate symptoms associated with mild to moderate depression; (b) is associated with mental health benefits such as improved self-confidence (at least in children and adolescents) and social skills (at least in mentally retarded individuals); (c) is associated with reduction of symptoms of anxiety and perhaps with improved mood; and (d) may alter some aspects of the stress response and coronary-prone (Type A) behavior.

Most recently Plante \& Rodin (1990) examined the developments in the literature on exercise and psychological health from 1981 to 1990. Their review, which examined studies using non-clinical populations, again found that exercise improves mood, self-esteem, and overall psychological well-being, while decreasing anxiety, depression, and stress. These articles helped confirm exercise as a viable treatment option for many of the most common client ailments. 


\section{An Operational Definition of Exercise}

Prior to discussing exercise and how it can relate to therapy, it would be helpful to put forth the accepted definitions of this term in the relevant literature. In his work involving exercise as an element in therapy, Brown (1986) defined exercise as "a physical activity that leads to the maintenance or improvement of a person's level of physical fitness" (p. 71). In their review, Folkins and sime (1981) only considered studies that employed cardiovascular models of fitness rather than simple motor ability or muscle strength, contending that cardiovascular efficiency is "the best indicator of level of physical fitness" (p. 375). Cooper (1970), in operationalizing "aerobic" dance spoke of "regular, vigorous physical exercise" that elevates the heart rate and is practiced for 20 minutes at least three times per week.

In an attempt to publish guidelines that outline the minimal levels of exercise necessary for achieving maximum physiological benefits, the American College of Sports Medicine (1980) put forth the following recommendations: (a) the type of exercise should require continuous activity involving large muscle groups and be aerobic in nature; (b) the activity needs to be performed at least three times per week; (c) the 
duration of the activity needs to be continuous for 20 or 30 minutes, or until 300 kilocalories are burned; (d) the activity should be performed at 70 to 85 percent of a person's age-adjusted maximal heart rate, or until the resting heart rate following exercise is between 140 and 187 beats per minute.

It should be noted, however, that not one of the aforementioned studies assessed follow-up psychological functioning to determine if psychological improvements were maintained after an exercise program was completed. Therefore, it has been concluded (Plante \& Rodin, 1990) that "it is impossible to determine either the minimal or optimal frequency and duration of exercise necessary for achieving and maintaining significant psychological improvements" (p. 19).

\section{Exercise and Psychotherapy}

Mental health professionals have historically tended to view psychological problems as separate from physical ailments. In addressing the issue of philosophical dilemmas in the field of psychology, Eaker (1972) suggested that "the mind-body problem is relevant to contemporary psychology only to the extent that the dualistic nature of man remains unchallenged" (p. 563). Stachnik (1980) pointed out 
that the most common medical problems that we now see in this country are behavioral, thus reflecting that our discipline is faced with the important role of supplying the required psychological interventions. The prevalence of problems such as depression and anxiety challenge health professionals to make continued improvements in treating these disorders. One promising area of research has focused on the inclusion of physical activity as part of a therapeutic treatment plan (Brown, 1986). Some specialists in this area contend that psychologists need to progress from a narrow, conservative style of therapy to one that utilizes components from the behavioral, social, and medical sciences (Thoreson \& Eagleston, 1985).

An important issue that has arisen over the past fifteen years is the question of the health beliefs and practices of psychotherapists. Aside from three studies however, (Barrow, English \& Pinkerton, 1987; Burks \& Keeley, 1989; Royak-Schaler \& Feldman, 1984), the issue has not been extensively addressed in the psychological literature. As early as 1976, the American Psychological Association Task Force on Health Research examined this issue and concluded that "psychologists are well-equipped to discover, delineate, and demonstrate the organismic nature of human beings and to 
encourage the realization that the total functional health of human beings is threatened whenever either side of the interactive mind-body equation is neglected" (Royak-Schaler \& Feldman, 1984, p. 705).

In a 1984 study by Royak-Schaler \& Feldman, less than half of the therapists surveyed considered dealing with issues of physical health and exercise to be an appropriate task for the therapy setting. Although they reported that 44 percent of their respondents engaged in regular exercise, only 47 percent felt it important for the psychotherapist to assess a client's physical health status upon intake. The authors did not attempt to evaluate the reasons why therapists might consider these issues to fall outside of the psychotherapeutic domain, but pointed toward the critical need to determine the perceived barriers in evaluating physical health and making health related recommendations.

Barrow, English \& Pinkerton (1987) found that 71.43 percent of the 196 responding psychotherapists engaged in regular exercise and most reported that they would be inclined to recommend regular exercise to their clients. Of the 140 therapists indicating engagement in regular physical fitness training, almost all believed that exercise enhances psychological functioning. However, the investigation went on to conclude that 53 
percent occasionally recommended exercise and only ten percent recommended it on a consistent basis.

Burks \& Keeley (1989) conducted a study assessing the beliefs and practices of psychotherapists toward both diet and exercise therapy. The authors found that $56 \%$ of the 232 responding therapists reported getting regular exercise for at least 20 minutes three times per week. Despite their findings that almost two thirds of their respondents had a favorable attitude toward exercise, the psychotherapists were inclined to address exercise with their clients infrequently, and much less often than other health behaviors, such as alcohol consumption, drug use, and sleeping habits. The authors concluded by proclaiming the importance of practicing psychotherapists to reassess their knowledge of exercise, and evaluate the basis upon which they are making decisions to include exercise as a part of their psychotherapeutic treatment practices.

In these three studies, it is apparent that most therapists believe in the efficacy of regular exercise and tend to engage in various forms of physical activity. We can also conclude that therapists who believe in the efficacy of exercise are willing to recommend exercise to their clients, but for some reason, tend not to do so. An ensuing step should be to 
evaluate the reasons why therapists might not address exercise in therapy, as well as the reasons that they may. Other issues that warrant further attention include assessing possible differences in the orientation and gender of the therapists.

\section{Purpose of the study}

There are a number of problems in the studies described so far. Specifically, many of the therapists were unable to accurately respond to the survey items due to a lack of standardization in the questions. In many cases, the discussion of exercise was related to a clinical case and a particular situation. The aforementioned three studies (Barrow, English \& Pinkerton, 1987; Burks \& Keeley, 1989; Royak-Schaler \& Feldman, 1984) failed to regulate the circumstances under which a psychotherapist would or would not include exercise as a component in a treatment plan, and also failed to provide analyses regarding specific reasons why exercise may or may not have been addressed in therapy.

The primary purpose of this study was to investigate the specific reasons that therapists do or do not discuss exercise with their clients in the therapy setting. An attempt was also made to understand 
issues such as how beneficial psychotherapists consider exercise to general psychological functioning, who is more likely to raise the issue of exercise in therapy, how therapists' personal exercise practices relate to their therapeutic discussions, and the relationships between demographic variables such as age, orientation, and gender differences.

The study attempted to answer the following questions: (1) what are the specific reasons that therapists do or do not discuss the issue of exercise with their clients in therapy? (1a) What specific benefits of discussing exercise are proposed by therapists who perceive exercise as beneficial to psychological functioning? (1b) What are the contraindications of addressing exercise proposed by therapists who do not believe exercise to be beneficial? (2) Do therapists who engage in regular aerobic exercise raise the issue of exercise and actively discuss exercise with their clients more often than those who do not? (3) How does therapeutic orientation affect attitudes and practices of therapists in discussing exercise with their clients? (4) How does the gender of a therapist and the gender of a client affect the likelihood of discussing exercise in psychotherapy? 


\section{C $\begin{array}{lllllll} & \mathrm{A} & \mathrm{P} & \mathrm{T} & \mathrm{E} & \mathrm{R} & 2\end{array}$}

METHOD

\section{Subjects}

There were two groups of subjects in this study, a group of 110 therapists who responded to a survey, and a small group of four local practicing therapists who served as interviewees.

Survey Respondents. Using the National Register of Health Providers in Psychology (1989 edition), 250 psychotherapists were randomly selected to participate in the study. All therapists listed in the National Register are currently licensed, and it is assumed that they are or have been involved in psychotherapy or counseling. Disproportionate random sampling was used to select an equal male/female sample. Responses were received from 110 of those surveyed, a rate of $44 \%$. of the respondents, 56 were male (51\%), and 54 were female (49\%). Respondents ranged in age from 31 to 72 , with a mean age of $48.54 ; 14.5 \%$ were between the ages of 31 and $39,50 \%$ between 40 and $49,21.8 \%$ between 50 and 59 , and $13.6 \%$ were 60 or older. The majority of the respondents reported engaging in a private practice $(77 \%)$; other responses included working in a hospital (8.2\%), 
outpatient private clinic $(6.4 \%)$, other setting $(6.4 \%)$, university affiliated psychological services center $(4.6 \%)$, community mental health center (1.8\%), and health maintenance organization (1.8\%). The most frequently treated client population was comprised of adult individuals ( $92.7 \%)$, followed by children (2.7\%), adolescents $(1.8 \%)$, couples $(0.9 \%)$, and families $(0.9 \%)$. Primary orientation was described by $33.6 \%$ as psychodynamic/psychoanalytic, $29.1 \%$ as cognitivebehavioral, $22.7 \%$ as eclectic, and $5.5 \%$ as some other orientation (e.g., feminist, systems, Gestalt, Rogerian). Furthermore, a number of respondents indicated an integrative approach; $6.4 \%$ as eclectic/psychodynamic/analytic, and $1.8 \%$ as eclectic/cognitive-behavioral. The respondents had practiced psychotherapy from 4 to 40 years, with a mean of 16.9 years.

Interviewees. Four locally practicing therapists were selected to provide more in-depth information regarding attitudes toward discussing exercise in the therapy setting. The two males and two females ranged in age from 35 to 44 years and had practiced psychotherapy from 5 to 16 years, with a mean of 10.8 years. Three of the therapists were involved in a 
private practice, while one practiced in a health maintenance organization, and all were in some way affiliated with the graduate program at the University of Massachusetts. Two of these therapists reported primary theoretical orientations as psychodynamic, one as cognitive, and one as eclectic.

\section{Instrument}

Survey subjects were mailed a cover letter, along with a 15-item, two page questionnaire, which they were asked to complete and return in an enclosed, selfaddressed, stamped envelope. The cover letter explained the nature and purpose of the study, where and why it was conducted, the approximate completion time, and instructions on how to contact the investigator in case questions or problems arose (see appendix A).

All responses to the questionnaire were made anonymously. The first page presented six demographic questions, including age, gender, practice setting, client population, therapeutic orientation, and years in practice. A brief clinical case vignette (see appendix B) was provided as a standardized stimulus that respondents used to indicate the likelihood that exercise would be addressed, as well as what therapeutic approaches might be utilized. The case vignette 
included symptoms believed to be most treatable using an exercise component of therapy (mild depression, anxiety, low self-esteem). A seven-point Likert-type scale was provided for therapists to indicate the likelihood that the topic of exercise would be addressed with a client such as this. For the purpose of this study, exercise was defined as "a continuous activity involving large muscle groups, aerobic in nature, and performed for at least 20 minutes at one time."

A number of questions were presented to assess attitudes about the discussion of exercise in psychotherapy. These included the relationship between client gender and the discussion of exercise, attitudes about the general relationship between exercise and psychological functioning, the issue of whether exercise is discussed with clients, the question of who is more likely to raise the issue, and the specific reasons that exercise is or is not discussed during the therapy session. Finally, subjects were asked about the amount and types of exercise practiced personally.

\section{Procedure}

The procedure for this study involved three steps: a brief analysis of previously collected clinical data, a large mailing of attitudinal surveys to professional 
psychotherapists, and personal interviews with four experienced therapists.

Step 1: Clinically Informing the Issue. In order to get a sense of current practices regarding the use of exercise in therapy, previously collected clinical data that had been gathered in the Psychological Services Center at the University of Massachusetts / Amherst were reviewed. The data had been compiled and computerized since 1984, and contained approximately 150 personal history questionnaires completed by clients, and over $560 \mathrm{clinical}$ case reports written by student therapists. Items pertinent to health were reviewed, such as client comments about exercise habits, and current versus ideal weight. Of the 110 clients who responded to the questions concerning their weight, $79 \%$ reported that their "ideal" weight was less than their current weight, and $26.4 \%$ showed a clinically significant difference between their current and ideal weight. Belloc \& Breslow's (1972) standard criteria for qualifying as significantly overweight (20 percent for men, 10 percent for women) was applied to determine clinical significance. Although being physically overweight is only one of several reasons why a therapist might raise the issue of exercise in therapy, it appeared to be a 
more obvious one. However, a complete search of the therapist records revealed that in only nine cases (1.5\%) was the word "exercise" even mentioned. Such low frequency strongly indicates the low likelihood that the topic was brought up during either the intake or therapy sessions.

Step 2: Questionnaire. Pilot questionnaires were given to six psychology graduate students and faculty members in order to check for errors and overall brevity and clarity. Materials were mailed to the 125 male and 125 female therapists selected from the National Register. All returns were received within six weeks following mailing.

Frequencies and percentages were computed on both the demographic and exercise items of the survey to assess general trends in the data. Since most of the questions contained nominal data, chi-square analyses were calculated to assess statistical significance of the relationships between these categorical responses. Correlations and analyses of variance (ANOVAS) were computed between items containing continuous data to determine the association of demographic and attitude variables with therapists' likelihood of addressing the issue of exercise in therapy. Open-ended survey items 
were collapsed into coded categories by two independent raters to establish reliability.

Step 3: Personal Interviews. In order to obtain more in-depth information regarding attitudes toward discussing exercise in the therapy setting, four personal interviews were conducted with experienced psychotherapists practicing locally. The interviews were designed to assess the practices and attitudes of the therapists regarding the therapeutic intervention of exercise, and to obtain their reactions to and impressions about the survey data. All interviews were audiotaped. The detailed responses of the therapists served to complement the survey material. 


\section{H A P T E R 3 \\ RESULTS AND DISCUSSION}

\section{Overview of Subject Attitudes}

In this section, the four foci of the study are addressed by presenting the statistical findings from the survey data along with more detailed information and case examples from the interviewees and written comments provided by the survey respondents. Before addressing the major research questions of this investigation, an overview of the general attitudes of the respondents is provided.

As stated previously, exercise involves a continuous, aerobic activity using large muscle groups, performed for at least twenty minutes at one time. The questionnaire presented six levels of exercise regularity, and respondents were asked to indicate from one to six, how often they exercised. The choices were: (1) more than three times per week, (2) two or three times per week, (3) once per week, (4) less than once per week, (5) less than once per month, and (6) never. The full range of responses was obtained, with a mean of 2.03 and a standard deviation of 1.24 , indicating an average rate of exercise between once and three times per week. The amount a therapist exercises is related 
to how beneficial he or she feels exercise is to psychological functioning, $\chi^{2}(25, \underline{N}=108)=64.00$, $\mathrm{p}<.001$. This result seems intuitive, for it makes sense that people who believe in the positive effects of physical exercise would be likely to want to experience those benefits personally. This relationship was viewed as important by all respondents and interviewees who engage in some form of exercise. In the words of one interviewee, "I've always been very sports minded and interested in exercise. I know how good it is and what it does for me mentally." Furthermore, the amount a therapist exercises was related to how likely it is that the therapist addresses the issue of exercise in the clinical case vignette, $x^{2}(30, \underline{N}=109)=50.77$, $\mathrm{p}<.05$. Although there are several other reasons that therapists address exercise in psychotherapy, this finding illustrates the importance of a therapist's own exercise habits in influencing his or her work with clients.

Types of Exercise. The survey respondents specified various types of personal exercise: $42.7 \%$ engage in walking, $24.5 \%$ in weight lifting, $23.6 \%$ in running, $23.6 \%$ in bicycling, $16.3 \%$ in organized sports, $13.6 \%$ in swimming, and $34.5 \%$ in some other form of 
aerobics (see Table 1). Respondents were classified into the categories of aerobic exerciser, nonaerobic exerciser, and non-exerciser. Of the total survey respondents, $78.2 \%$ reported that their exercise is aerobic in nature, $15.5 \%$ reported that they exercise, but not aerobically, and 5.5\% reported either activities that are not "exercises," or stated that they do not exercise at all. The variables of exercise regularity and type of exercise were then collapsed to create a subset of therapists whose exercise habits conform to the definition of exercise put forth in the study. Frequent aerobic exercisers (performing aerobic exercise at least two or three times per week for a period of at least 20 minutes per session) were more likely to feel that exercise in general is beneficial to psychological functioning, $x^{2}(2, \underline{\mathrm{N}}=107)=19.94, \underline{\mathrm{p}}<.005$, than those therapists who exercise less frequently, or less vigorously. This finding was supported by comments made by several survey respondents as well as interviewees. In the words of one interviewee:

I try to do two or three times per week for 20 minutes at least. I think it's a really important thing to do, it's been part of my own experience. . If I run, I feel great, so I have personal experience to back it up. 
Table 1

Types of Exercise Engaged in by Psychotherapists

\begin{tabular}{|c|c|c|}
\hline Exercise & $\% *$ & $N *$ \\
\hline Walking & $42.7 \%$ & 47 \\
\hline Weight Training & $19.1 \%$ & 21 \\
\hline Aerobics & $17.3 \%$ & 19 \\
\hline Running & $15.5 \%$ & 17 \\
\hline Exercise Bike & $14.5 \%$ & 16 \\
\hline Swimming & $13.6 \%$ & 15 \\
\hline Bicycling & $10.9 \%$ & 12 \\
\hline Tennis & $8.2 \%$ & 9 \\
\hline Jogging & $6.4 \%$ & 7 \\
\hline Racquetball & $5.5 \%$ & 6 \\
\hline Rowing Machine & $5.5 \%$ & 6 \\
\hline Muscle Toning/Calisthenics & $5.5 \%$ & 6 \\
\hline x-country ski Machine & $4.5 \%$ & 5 \\
\hline Stairmaster & $4.5 \%$ & 5 \\
\hline Golf & $3.6 \%$ & 4 \\
\hline skiing & $2.7 \%$ & 3 \\
\hline
\end{tabular}

* Note: Percentages and numbers exceed $100 \%$ and 110 due to the fact that some respondents specified more than one type of exercise in which they engaged. 
Therapist Age Differences. Another interesting but unexpected set of findings concerned the relationship between therapist age and various demographic and exercise variables. First, younger therapists indicated that they are more likely to exercise more frequently than older therapists, $\underline{F}(5,103)=2.52, \underline{p}<.05$. Although this result seems intuitive, significance is probably due more to physical factors and less to age differentiated attitudes. Many older respondents reported that they had exercised when they were younger, but are now unable due to medical reasons or physical limitations. It is also possible that older respondents still exercise, but not at a level that meets the accepted definition of exercise.

Second, in specifying therapeutic approaches that came to mind in reference to the clinical vignette case, younger therapists indicated that they would be somewhat more likely to use a cognitive-behavioral approach, and older therapists more likely to use a psychodynamic, or psychoanalytic approach, $\underline{F}(5,102)=2.45, \underline{p}<.05$. This finding might be due to the fact that cognitivebehavioral techniques are relatively new compared with the well-established and more traditional techniques of psychoanalysis and psychodynamic therapy. Furthermore, with the steady shift toward a more eclectic model in 
our training programs, it is possible that younger therapists have had greater exposure to cognitivebehavioral training. Another possibility that arose was that therapists may have a tendency to become less prescriptive and more insightful later in their careers. one interviewee made the following observation: "I think what has influenced my development as a therapist is my clients. I've gotten more dynamic as I have gotten older."

\section{Reasons Why Exercise Would be Discussed}

The first focus of the study addressed the specific reasons that therapists do or do not discuss the issue of exercise with their clients in therapy. Survey respondents listed up to three different reasons for discussing or choosing not to discuss the topic, and these responses were collapsed into distinct categories (see Table 2).

Symptomatic Benefits. The most frequently indicated reason that a therapist would be inclined to address the issue of exercise in therapy is for symptomatic benefits $(82.7 \%)$, including the alleviation of anxiety and depression, relaxation, and the management of tension, stress or anger. Many of the 
Table 2

Reasons Therapists Do or Do Not

Discuss Exercise with Clients

Reasons For Discussing

$\%$ N $*$

Perceived symptomatic benefits

$82.7 \% \quad 91$

Could give the client a sense

of mastery

Body benefits

$37.3 \% \quad 31$

$22.7 \% \quad 25$

Could enhance the therapeutic

relationship in general

$9.1 \% \quad 10$

Social benefits

$9.1 \% 10$

Reasons Against Discussing

$\% \quad \mathrm{~N}$

Inappropriate/too directional

$13.6 \% \quad 15$

Too demanding/could confuse the

therapeutic relationship

$11.8 \% \quad 13$

Could foster client sense of failure

$3.6 \% 4$

Could fuel client resistance

$1.8 \% 2$

could be perceived as insensitive

by the client

$1.8 \%$

2

Note: Percentages and numbers exceed $100 \%$ and 110 due to the fact that each respondent gave up to 3 reasons why they do or do not discuss exercise with clients. 
survey respondents address the issue of exercise with clients because they believe that exercise leads to an overall feeling of well-being. One interviewee commented that her knowledge and beliefs about the efficacy of exercise had been greatly informed by the abundance of current, professional literature on the topic. One respondent stated, "I know exercise alleviates depression, so I advocate it for those with depression, and who lack energy." Also, more than half of the subjects who were either less inclined to address exercise in the vignette case or who responded that they felt exercise was not beneficial or only slightly beneficial to psychological functioning (54.8\%) still indicated they would discuss exercise with their clients at some time because of the perceived symptomatic benefits.

Although most respondents believe symptomatic benefits to be a good reason to address the issue of exercise in therapy, some offered circumstances where it may be contraindicated. An example would be the case when a client shows symptoms of mild depression or anxiety but also presents with a medical problem. Some therapists feel that there are circumstances where treatment priority should be given to medical conditions. One interviewee gave an interesting example 
of the possible contraindication of exercise in the treatment of anxiety. In this case, the client was suffering from panic disorder, yet also had heart problems. There was a family history of heart arrhythmia and in fact, the client's father had died as a result of heart failure while engaged in strenuous activity. The client felt he desperately needed to exercise but was terribly afraid of the potential consequences.

Enhancement of the Therapeutic Relationship. Several respondents had the impression that the discussion of exercise might positively affect the therapeutic relationship; $9.1 \%$ indicated that they felt such discussion would enhance the bond between their clients and themselves. It appears that this viewpoint stems from a belief in the nonspecific benefits of establishing a healthy therapeutic bond. Frank (1976) discussed several shared features that are beneficial and common to all effective psychotherapies, including a confiding client-therapist relationship, and a healing setting. It is plausible that the discussion of exercise is being viewed by some respondents as a part of this healthy and confiding relationship. Some therapists may also feel that giving an assignment to a 
client fosters an active involvement in therapy. One commented that "Discussing exercise provides an opportunity to assess a client's level of motivation and involvement in therapy," while another felt that exercise will make a client more relaxed, and "being more relaxed furthers treatment." One interviewee suggested that the relationship enhancement benefits can extend to more seriously impaired populations:

When I was in a residential treatment facility working with psychotic clients, I would sometimes go jogging, and sometimes clients would join me. It was a wonderful way for me to connect with some of them. For many of them, sitting down and having a conversation would be terrifying. But if we were out doing things, being active, they could often handle it better.

\section{Client Sense of Mastery. Respondents also} specified that discussing exercise can enhance the client's sense of mastery or self-esteem (37.3\%). If a client comes to therapy experiencing feelings of failure or an inability to cope with various aspects of daily life, the intervention of exercise may provide a means of feeling more accomplished and therefore improving overall self-image. Perhaps it was also felt that 
giving clients a manageable task could increase their sense of control. Once the client regains that sense of control, other issues that he or she may have been unable to address can be brought up in the therapy. Providing a sense of control can also be accomplished by exercise if a client experiences difficulty depending on others. A client who is engaging in self defeating behaviors by refusing to accept conventional forms of treatment may be able to benefit from an exercise intervention. For example, a depressed client who is not responding to talking therapies and is wary of medications may be able to experience symptom relief as well as a sense of accomplishment by "self-medicating" with exercise. Exercise could also act as a distraction from other problems in such a case. An interviewee gave an interesting example of how exercise can offer this sense of mastery and empowerment in hospitalized psychotic clients:

One of the therapists had the idea of doing some intense, vigorous physical activity, and we took the clients rock climbing. There was a combination of teamwork, and a sense of depending on one another. In having to deal with some of their fears, the clients started talking more to one 
another, being more active and more outspoken, and establishing more of a sense of control.

Social Benefits. The social benefits of exercise were mentioned by respondents and interviewees as additional reasons the topic of exercise might be addressed with a client (9.1\%). Some therapists may feel that exercise leads to social interaction and increased contact with others, which is especially important in cases involving a shy client, or a person who displays awkward or inappropriate social skills. Focusing on social benefits by using exercise can also be helpful in cases involving a more seriously impaired client who demonstrates marked isolating tendencies.

Furthermore, several respondents mentioned the effectiveness of exercise as a means of increasing socialization with a partner or peers, and as a way to spend more time together with family members. A number of therapists may have felt that group exercise would provide interpersonal camaraderie benefits for a client interested in organized sports activities, but who is underutilizing his or her talents due to uneasiness around other people. This point was illuminated by an interviewee's relating the case of an athletic 12-yearold boy suffering from separation anxiety: 
I was very interested in promoting exercise, not so much as an aid to his mood, but to get him out of the house and doing something with other kids. That's the basis for kids getting out and being with other kids, exercise. He had separation anxiety, so I would reward him for say, spending more and more time on the basketball court, not so much for the sake of exercise, but for the socialization benefits involved.

Body Benefits. Overall physical benefits accounted for $22.7 \%$ of the reasons that respondents gave for addressing exercise with their clients in psychotherapy. One example where a therapist might feel that the discussion of exercise is warranted would be with a client who is in poor physical shape due to a weight problem. Addressing the issue of exercise would most likely take place in this circumstance if the client was experiencing psychological problems related to being overweight (such as low self-esteem, depression, or interpersonal problems) or if general physical conditioning was directly related to a client's presenting problem. Therapists might feel that if a client is experiencing problems related to body image issues, the discussion of exercise would have an 
appropriate place in the therapy. This sentiment was expressed by a respondent who strongly advocated the use of exercise as an intervention for clients who are out of shape, and therefore lacking energy. Another respondent expressed similar feelings in stating that exercise should necessarily be addressed in cases where a client is overweight. It would seem that these opinions were offered due to the perceived connection between physical conditioning and the variety of previously mentioned psychological factors. In addition, approximately $3 \%$ of the therapists specified that they would bring up exercise to aid in metabolism or in cases of chronic pain management or psychomotor retardation.

Therapy context. Therapists might be inclined to address the role of exercise in therapy due to the setting in which they are practicing. A therapist involved in a private practice may generally see a limited range of clients compared to a therapist who is working in a hospital, medical clinic, or health maintenance organization. Although this need not be the case, as private practitioners may be quite specialized, one interviewee working in a health maintenance organization felt more likely to come in contact with 
clients who have medical problems compounded by psychological problems:

Working in a general medical clinic, I see a much broader range of clients than someone working only in a therapy office. My clients often come to me because of psychological problems which are aggravating their medical problems. I tend to see clients who need a more general health treatment. This therapist gave a further example of working extensively with HIV-positive clients, stating that being in this type of setting allows the comfortable discussion about the positive effects of exercise on the immune system. For therapists who are affiliated with hospitals and health maintenance organizations, it is possible that the preventative treatment focus of these medical facilities has the effect of a greater emphasis on exercise and physical issues. Unfortunately, only 11 respondents practiced in medical settings, so statistical analyses were not possible.

Reasons Why Exercise Would Not be Discussed

Perceived Inappropriateness. The reason most survey respondents gave for not wanting to discuss exercise in therapy was because they felt it is too 
directive, and therefore an inappropriate therapeutic action $(13.6 \%)$. It would appear that many therapists simply do not see their work as pertaining to the body, and that in general, clients come to therapy to discuss psychological ailments, not physical and exercise related ones. Respondents who shared this view tended to feel that exercise falls in the domain of the physician and recreational therapist, and that it is a subject not to be broached by the mental health professional. Other therapists simply consider physical issues to be out of their area of practice.

The recommendation of exercise can be considered inappropriate in therapy because the topic of exercise may be seen to fall under the heading of being suggestive and offering prescriptions to clients. It is also possible that some therapists could see using exercise in this way as destructive to the growth of the therapy. One respondent exemplified this by reporting, "I would never suggest it, since suggestions are not helpful in psychotherapy and are in fact counterproductive." One interviewee shared this feeling, stating that although he routinely questions clients about health, diet, and how much they exercise, he feels that he would not necessarily push it too much 
once he found out about it. "There is a limit to how much you can tell a client to do."

Confusion of the Therapeutic Relationship. Several respondents felt that in addressing the role of exercise, they would feel too demanding of their clients, and that this could confuse the therapeutic relationship (11.8\%). Some therapists, especially those who tend to work within a psychodynamic or psychoanalytic model, might feel that this could lead to a complication of transference and countertransference issues. For example, if a therapist is working reflectively with a depressed client and suddenly raises the issue of exercise, the client might become confused with the abrupt shift in treatment modalities (Halgin \& McEntee, in press).

The therapeutic relationship could become compromised if the mention of exercise is construed by the client as a personal preference of the therapist. This could be problematic if the client feels that he or she must take the therapist's advice solely for the purpose of carrying out his or her wishes. Most therapists would undoubtedly agree that this type of relationship is not constructive for the client. On the other hand, a respondent made the point that in his 
experience, if he made any kind of suggestion during the therapy session, the client would rarely follow through with it. One interviewee shared this viewpoint and offered the following:

If you insist that clients do something that for a variety of reasons they cannot or do not want to do, and you repeat it too much, they will start seeing you as authoritarian and not caring, and you will start seeing them as incapable and unmotivated.

client Sense of Failure. Creating a sense of failure in the client would be a possible result of discussing exercise in therapy according to $3.6 \%$ of the survey respondents. It is conceivable that the therapist raising the issue of exercise could be seen by clients as giving them yet another thing to do and thus setting them up for failure. Some therapists may feel that the practice of assigning exercise could further introduce problems into the therapy by placing unreasonably high expectations on the client. One interviewee illustrated this by offering the example of a client who agreed that running would probably make him feel better: 
He went out and ran seven miles, two days in a row, and then couldn't do it again. I told him to just go for a walk at first, but it was just part of his character to overdo it in a masochistic way and then collapse and not want to get out of bed. It was a narcissistic problem; everything he did, he wanted to be the best at.

An observation about the relationship of exercise and control was also made by an interviewee who felt that "clients who are inclined to exercise will exercise more when they are more in control of themselves, and their lives." This statement makes sense, yet implies somewhat of a "catch-22" for the client, especially for depressed clients who might lack the energy and motivation to begin exercising. A sense of failure may again be promoted if a therapist suggests that a client exercise in order to be more in control of his or her life, when the client may need that sense of control before turning his or her attentions to "selfmedication" through exercise.

Therapist Insensitivity. Another contraindication for addressing exercise that respondents reported was the feeling that it would be construed as insensitive and demeaning by their clients (3.6\%). Therapists would 
need to be careful not to degrade a client by crassly suggesting exercise to a client who is physically unable to engage in strenuous activity. Furthermore, suggesting exercise would be seen lacking sensitivity to a client who had body image issues.

Perhaps therapists believe that engaging in a discussion about exercise in therapy would be discounted by the client. One survey respondent elaborated on this point by stating that "Suggesting exercise seems simplistic. Does anybody not think exercise is good? Maybe therapists don't think to suggest exercise since everybody already knows exercise is good for one." An interviewee had a similar view in suggesting the following:

Most adults know about exercise. It's in the news all the time, it's not something they don't know about. So you don't feel like you're depriving your clients from essential knowledge by not bringing it up.

Client Resistance. Although only mentioned by a few survey respondents (1.8\%), some therapists are concerned that addressing exercise in therapy might fuel client resistance. Perhaps the mention of exercise as a possible treatment option might trivialize other issues. 
By focusing on exercise, the client may be distracted from discussing other potentially important topics. Therapists might be concerned if a client became overinvolved with exercise, to the extent that it became a central focus of the therapy. Although in some cases this might be acceptable, other issues would become obscured, as would be the situation with any obsession. In the words of one survey respondent: "Discussing exercise can become obsessional and serve as resistance."

Therapist Unfamiliarity. A few respondents noted that they are not inclined to address exercise with clients because they are personally unfamiliar with the differing forms of exercise. Apparently these therapists felt that their own knowledge of exercise was necessary in order to feel competent about bringing the topic up in therapy. On a related topic, some therapists are concerned about potential dangers involved in physical overexertion. This point prompted several respondents and interviewees to caution that a referral to a physician should always be made before a client commences on an exercise regime. One survey respondent expressed his feeling that therapists should practice what they preach by stating that he "would not 
recommend that a therapist who does not exercise advise a client to do so."

Eating Disorders. Cases of bulimia and anorexia have engendered a great deal of controversy around the pros and cons of addressing the role of exercise. Some therapists have adamantly argued that exercise can be very dangerous in these cases, both physically and psychologically. However, others have maintained that being able to therapeutically examine a tangible example of a client's disturbance provides a telling picture of his or her obsessions and compulsions.

One interviewee related an interesting case of a borderline woman, bulimic and 50 pounds overweight, who presented with feelings of "tremendous hate for her physical appearance." The client began managing her eating binges by exercising incessantly for several days. Although she lost 50 pounds, which was seen as positive, the therapist did not discuss the issue of exercise for fear of introducing something that might be physically dangerous, psychologically ill-advised, and therapeutically premature.

This sentiment was echoed by two other survey respondents who specialized in working with anorexic and bulimic clients; they offered that in eating disorder 
cases, exercise is often performed excessively and dangerously, and must therefore be approached cautiously, and necessarily viewed as a negative in the therapy setting. Another interviewee disagreed however, and related a case example of a bulimic woman:

Using exercise got to be a chance for her to externalize issues and work with them. It has helped her in feeling more comfortable in talking about the obsessions and compulsions that she has. Talking about it around the context of exercise has been easier for her to do, so I would argue that it is not contraindicated because exercise would be used like anything else in her life.

Other Reasons. Although the preceding reasons for and against addressing the role of exercise in psychotherapy were the most common brought up by survey respondents and interviewees alike, there were a few other less popular, but valid ideas worth mentioning. A few therapists cited the discussion of exercise as a means to help reduce drug, alcohol and nicotine dependence. These therapists pointed toward the professional literature as influencing their views about the relationship between physical activity and reduced substance dependence. One respondent also offered that 
rigorous physical exercise can also help alleviate physical and psychological withdrawal symptoms. One interviewee, who does not discuss exercise in therapy as a general rule, stated that it was regularly discussed in cases where the client was a smoker.

Two of the interviewees and a number of the survey respondents stated that they regularly address the issue of exercise as part of an overall health assessment at the beginning of a therapy with a new client. However, most commented that information that is gathered during this general history interview is usually set aside until a more appropriate time, if it is used at all. Choosing not to discuss exercise in therapy was expressed as a valid option when working with populations other than individuals. Family therapy might not be a suitable situation in which the topic of exercise is addressed because exercise tends to be an individual and personal matter. When working with a family, there are usually larger, more pressing dilemmas to address, such as problems involving interpersonal communication, which tend to deemphasize individual issues. 


\section{Efficacy Belief Differences}

The study was also concerned with whether raising the issue of exercise and actively discussing exercise in therapy is related to therapists' beliefs about the efficacy of exercise. It was noted earlier that therapists who engage in aerobic exercise at least two or three times per week for a period of at least 20 minutes per session were more likely to indicate that exercise in general is beneficial to psychological functioning than those therapists who exercise less frequently, or less vigorously. These "true exercisers," therapists who regularly engage in exercise as defined by the study, indicated that they are more likely to raise the issue of exercise with their clients than therapists who exercise less frequently or less vigorously, $\chi^{2}(2, \underline{\mathrm{N}}=105)=12.44, \underline{\mathrm{p}}<.005$.

Furthermore, the true exercisers are more likely to discuss exercise with their clients in general, $x^{2}(1, \underline{\mathrm{N}}=109)=9.10, \underline{\mathrm{p}}<.05$. This finding may suggest that therapists who are personally engaged in exercise tend to feel more comfortable discussing exercise with their clients. Interviewee subjects differed in their opinions regarding this relationship. one interviewee stated, "I think the fact that I exercise makes a big difference in the relationship." 
Another disagreed:

My own exercise habits have not influenced my therapeutic work, but I see the literature as being connected to my own feeling about myself and my clinical work. I think the literature has influenced my behavior, because of the relationships found between exercise and emotional state.

A Pearson correlation revealed that those therapists who hold general beliefs that exercise is beneficial to psychological functioning were more likely to include exercise as a treatment recommendation vis a vis the clinical case vignette, $\underline{r}(110)=.50, \underline{p}<.001$. Furthermore, the "true exerciser" therapists, those who engage in regular aerobic exercise, were more likely to address the issue of exercise in the vignette, $X^{2}(6, \underline{\mathrm{N}}=109)=15.55, \underline{\mathrm{p}}<.05$. These findings seem to further illustrate the importance of a therapist's own exercise habits in influencing his or her work with clients.

\section{Orientation Differences}

The relationship between therapeutic orientation and the attitudes and practices of therapists in addressing the role of exercise with their clients was 
assessed. Respondents indicated on a seven-point Likert-type scale the likelihood of addressing the issue of exercise in their treatment of a case such as that described in the clinical case vignette; the scale ranged from 1, (not at all likely), to 7, (extremely likely). The mean was 4.67 , with a standard deviation of 1.88 , and a range of 1 to 7 . Of the 110 total respondents, 29 specified the modal value of 6 , indicating that $26.4 \%$ of the respondents would be quite likely to address the role of exercise.

A trend was present that suggested that cognitivebehavioral therapists are more likely than psychodynamic or psychoanalytic therapists to specifically use exercise as an approach to the clinical case vignette. However, since only seven of the 110 survey respondents specified the approach of exercise ( $6.4 \%)$, no statistical significance could be detected. As would be expected however, therapists who define their primary therapeutic orientation as eclectic or cognitivebehavioral are more likely to use a cognitive-behavioral approach to the vignette than therapists who define themselves as primarily psychodynamic or psychoanalytic, $x^{2}(5, \underline{\mathrm{N}}=50)=39.53, \underline{\mathrm{p}}<.001$.

Contrary to what was expected, the survey respondents indicated that there was no relationship 
between therapist orientation and the likelihood that exercise would be addressed with the vignette client. In addition, it was also hypothesized that therapists' primary therapeutic orientation would be related to the likelihood of discussing or raising the issue of exercise in therapy. Again, these relationships were not shown to be statistically significant. These findings were particularly puzzling because all of the interviewees felt that a therapist's orientation would influence the likelihood that exercise would be addressed. One explanation for this finding is that more and more therapists are moving toward an eclectic or integrative therapeutic model. Even though the majority of respondents indicated an orientation other than eclecticism $(77.3 \%)$, most have at one time or another moved outside their primary modality. One psychodynamically oriented interviewee expressed the following thought:

I would think orientation would make a tremendous difference. I rarely give advice or make suggestions to people, only when I feel it is necessary. My not recommending exercise is more influenced by the fact that, due to my being psychodynamic, I rarely recommend anything specifically. 
Respondents indicated on a seven-point Likert-type scale their attitudes about the perceived benefits of regular exercise for psychological functioning; the scale ranged from 1 , (not at all beneficial), to 7 , (extremely beneficial). A mean of 5.77 was reported, with a standard deviation of 1.20 , and a range of 2 to 7. Again, contrary to what was expected, there was no significant relationship between therapist orientation and attitudes about how beneficial exercise is to psychological functioning. of the 110 respondents, 35 specified the modal value of 7 , indicating that $31.8 \%$ of the respondents felt very strongly that physical exercise positively affects psychological functioning, regardless of other variables. It appears that most therapists believe in the efficacy of exercise for psychological functioning in general, regardless of therapeutic approach.

\section{Gender Differences}

The final focus question concerned therapist gender differences in: (a) the likelihood of discussing exercise with male or female clients, and (b) attitudes and practices of addressing exercise with clients in general. Male therapists were more likely to discuss exercise with male clients than with female clients, 
$X^{2}(2, \underline{\mathrm{N}}=110)=8.12, \underline{\mathrm{p}}<.05$. Perhaps male therapists are just not as comfortable discussing exercise with female clients, because such a discussion may be considered too intimate a topic for male therapists to raise with female clients. One male interviewee suggested that "the whole thing about physical appearance is more loaded between men and women than it is between men and men." He went on to state that female clients might be more sensitive to comments about their body and physical appearance, perhaps construing such discussion as sexually charged. The increasing frequency of harassment cases and client suits in the health professions may be leading male therapists to take a more conservative approach to addressing potentially intimate topics with female clients in therapy.

An added explanation for therapist gender differences in discussing exercise with clients is that males are just more familiar with the various forms of men's exercises. It is possible that when the issue of addressing the role of exercise does arise in therapy with a male client, a male therapist may be more likely to offer suggestions, advice, or personal experiences than if the client were female. Also, a male therapist may simply be reticent to raise the issue with a female 
client because he is not versed in the various forms of female exercises.

of the female survey respondents, 53 out of 54 reported that the gender of the client would not affect the likelihood of discussing exercise in therapy. Perhaps female therapists do not feel the same societal pressures as males to avoid certain potentially sensitive matters. It might also be the case that female therapists are simply more comfortable discussing body related issues than are male therapists. However, one female interviewee had a different reaction than the female respondents, indicating that she would be more likely to address the issue of exercise with her male clients:

I am supportive of individuals who exercise, but I must admit, more with men than women. I think some of it is my own gender bias. I tend to think that for men, taking care of the body relates to exercise, while for women, taking care of the body relates to diet. I see exercise as being a more integral part of being a man than it is of being a woman.

The answers to the question of "what therapeutic approach comes to mind" in reference to the clinical case vignette, were collapsed and categorized into six 
groups: $45.5 \%$ of the therapists mentioned a cognitivebehavioral approach, 23.6\% mentioned a psychodynamic or psychoanalytic approach, and $11.8 \%$ mentioned some other approach, such as rational emotive, feminist, eclectic, or diagnostic testing. Of the respondents, $6.4 \%$ specifically suggested using exercise as part of a treatment plan, $8.2 \%$ felt "further evaluation" was needed, and $2.7 \%$ commented that the case was "too vague." There was a gender difference between male and female therapists and the therapeutic approach in reference to the vignette. Although males did not report being more cognitive-behavioral in orientation, males were more likely than females to use a cognitivebehavioral approach to the vignette case, $X^{2}(5, \underline{N}=108)$ $=13.06, \underline{\mathrm{p}}<.05$.

An additional trend was found when examining gender differences and therapeutic approach. All nine respondents stating that "further evaluation" was needed in assessing the vignette case were women, while all of the six respondents commenting that the case was "too vague" were men. Due to the small number of subjects in these cells, tests of significance could not be carried out. In an effort to explain this, one interviewee suggested that "I think that's the social psychological 
phenomenon that women internalize and men externalize. I think saying 'too vague' is another way of saying I need more information." 
C H A P T E R 4

CONCLUSIONS

The primary purpose of this study was to assess the many beliefs and attitudes that psychotherapists have regarding the discussion of exercise in the therapy setting. Central to addressing this issue was a detailed examination of the reasons put forth by therapists as to why the topic of exercise may or may not be brought up with their clients. It seems that the vast majority of the respondents were in fact, wellinformed about the current literature detailing the various symptomatic benefits of exercise. Regardless of demographic variables, therapists did acknowledge that exercise could be considered a viable treatment option in cases involving anxiety, mild depression, and low self-esteem. Therapists also pointed toward the beneficial effects of exercise as increasing selfesteem, enhancing the therapeutic relationship, enhancing social relationships, and promoting overall physical health. These favorable viewpoints seemed to stem from general beliefs in the efficacy of physical health in coping with psychological difficulties. It was interesting to note that most pro-exercise responses came from therapists whose beliefs and practices were 
largely self-informed; people who had benefited personally from exercise were more likely to want to relate those experiences to their clients. First-hand knowledge makes a difference in whether therapists reported that they do in fact address exercise in therapy, even though almost all therapists were familiar with the favorable literature on exercise efficacy. Many valid reasons for not choosing to address exercise in therapy were raised in this study. Because of therapeutic style and orientation, some therapists felt that the topic of exercise is inappropriate, insensitive, too directional, or too demanding an issue for therapy. Several people viewed exercise as a prescription, and thus were reluctant to discuss it since they did not see prescribing as part of their role as therapists. Perhaps this belief has also been perpetuated by training institutions, and this lack of training or expertise may play a part in therapists ' unwillingness to address exercise with their clients. Psychologists have historically tended to view physical issues as separate from psychological ones. The sentiment that exercise issues are better left to physicians and physical therapists seemed to ring true for many of the respondents. One possibility for this unwillingness is the current trend of increased 
specialization in the health fields in general. Despite the fact that more and more Americans are discovering the connections between health, fitness, diet, and psychological functioning, many physicians and psychologists retain a narrow scope of specialization. Therefore, it is possible that topics such as exercise, which bridge the gap between mind and body, are viewed as unimportant to health care providers interested in focusing their professional efforts.

of particular interest in the study were the differences between gender and certain attitudes toward discussing exercise. Although most survey respondents claimed that the gender of the client would have no effect on the likelihood of addressing exercise in therapy, several male therapists felt that they would be more likely to engage in such a discussion if the client were male. In trying to explain this, the male interviewees suggested that perhaps males are more comfortable and familiar with discussing body related issues with other men. An interesting point was raised regarding this topic, in that the discussion of body issues between males and females can be thought of as a loaded issue. Perhaps media attention regarding issues of sexual harassment has made some male therapists 
overly cautious in discussing anything pertaining to the body of their female clients.

Although female therapists tended to report no differences in attitudes about discussing exercise with male or female clients, there may indeed be a gender bias. Some female therapists may be more apt to discuss exercise with male clients due to their seeing exercise as a more integral part of being a man. A tendency for all therapists to address exercise more with men could be reflective of a society where female health and body image is so closely linked to diet, and male image is so closely linked to strength and physical fitness.

\section{Limitations}

Three limitations of this study must be noted. First, although "exercise" was specifically defined in the survey, there is probably a relatively wide range of connotations in the minds of those who participated. In categorizing therapists' preferred kinds of exercise, it was occasionally unclear whether respondents were considering their activities to be actual exercise or not. For instance, the most common form of exercise reported was walking. Vigorous power walking is one thing, but walking to your car is quite another. 
Second, there is a possibility that selection bias was a factor in the study. The $44 \%$ return rate indicates that many therapists receiving the survey did not choose to participate in the study. It is possible that some therapists chose not to respond based on feelings that the topic of exercise was not interesting or relevant to their work. It is conceivable that some of those who participated did so because of a particular interest in the topic of exercise.

Lastly, there is the possibility of a self-report bias by the survey respondents. Of the responding therapists, $75.5 \%$ reported that they engage in regular aerobic exercise. This percentage is higher than in other studies that have looked at exercise practices of psychotherapists; Barrow, English \& Pinkerton (1987) reported $71.43 \%$, Burks \& Keeley (1989) reported 56\%, and Royak-Schaler \& Feldman (1984) reported that $44.2 \%$ of their respondents engaged in regular exercise. Again, this discrepancy could be due to the possible effects of selection bias. However, it is feasible that the respondents were stretching either the definition of exercise or the frequency of their own exercise in an effort to portray themselves in a somewhat better light. 


\section{Future Directions}

There are numerous research avenues that would further illuminate some of the questions posed in this study. The future determination of the effects of discussing exercise in the therapy setting by means of a controlled outcome study would be one such option. It would also be helpful to examine in greater detail the gender differences, of both therapists and clients, regarding the beliefs and attitudes of the role of physical issues in psychotherapy. Also, as first suggested by Burks \& Keeley (1989), it would be important to examine how exercise issues are being addressed in training, and to what extent physical issues should be included in graduate training programs in general. 
APPENDICES

58 
SAMPLE COVER LETTER

November 8,1991

$x \times x x x \times x x x x x x, P h . D$.

$\mathrm{xxx} \quad \mathrm{xxxx} \quad \mathrm{xxxx}$

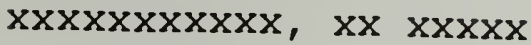

Dear Dr. xxxxxx:

We are writing to request your participation in a research project entitled, "Therapists' Attitudes Addressing the Role of Exercise in Psychotheres about are interested in determining exercise is discussed withing the extent to which and how therapists and how therapists feel about discussing exercise with their clients. We would like your help in answering
these questions.

This packet contains a very brief questionnaire, which should take no more than 5 minutes of your time. Your participation is voluntary, and will be kept strictly confidential. A summary of results will be sent to all interested respondents. If you wish to receive a copy, please so indicate on the attached label.

Please direct any questions, comments, or concerns regarding the manner in which this study is being conducted, to Derek McEntee at (413) 545-0051, Department of Psychology, Tobin Hall, University of Massachusetts, Amherst, MA 01003.

We would greatly appreciate you return of this questionnaire by November 22 nd. Thank you in advance for your participation.

sincerely,

Derek McEntee

Doctoral Candidate in Clinical Psychology

Richard P. Halgin, Ph.D.

Professor of Psychology 
APPENDIX B

QUESTIONNAIRE

DEMOGRAPHIC INFORMATION

1) Age

2) Gender M

F

3) In what type of setting do you MOST OFTEN practice therapy? (circle one)

1 Private Practice

2 University affiliated Psychological Services center

3 Community Mental Health Center

4 Hospital

5 outpatient Private $\mathrm{Clinic}$

6 HMO

7 other

4) Which client population do you MOST OFTEN treat? (circle one)

1 Individuals

2 Families

3 Couples

4 Groups

5 Adolescents

6 Children

5) What is your primary therapeutic orientation?

6) How many post-doctoral years of experience have you had as a therapist?

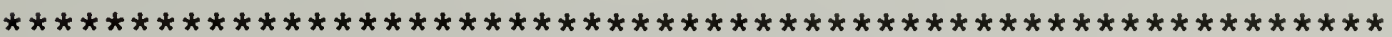
CLINICAL VIGNETTE

A 30-year-old client comes to you seeking professional psychological help. The client complains of feelings of low self-esteem, mild depression, mild anxiety, and moderate levels of stress. The client is apparently in good physical health and of average weight.

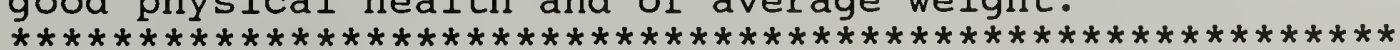


7) Realizing that this vignette is somewhat vague, what therapeutic approaches come to mind?

8) How likely is it that exercise would be addressed in therapy with this client? (circle one)

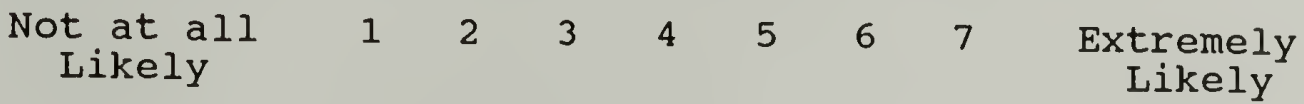

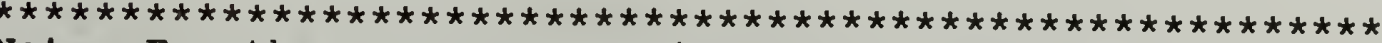

Note: For the purpose of this study, "exercise" is defined as: (a) a continuous activity involving large muscle groups; (b) aerobic in nature; and (c) performed for at least 20 minutes at one time.

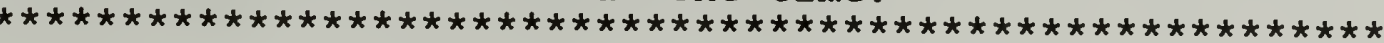

9) Please check one of the following:

The discussion of exercise would be more likely to occur in this particular case if the client were male.

The discussion of exercise would be more likely to occur in this particular case if the client were female.

The gender of the client would not affect the likelihood of discussing exercise.

10) In general, how beneficial do you feel regular exercise is to psychological functioning?

(circle one)

$\begin{array}{lllllllll}\text { Not at all } & 1 & 2 & 3 & 4 & 5 & 6 & 7 & \text { Extremely }\end{array}$ Beneficial

Beneficial

11) Do you ever discuss exercise with your clients? (circle one)

NO

12) If yes, who is more likely to raise the issue? (circle one)

ME THE CLIENT 
13) The issue of exercise may be raised by a client or a therapist. We are trying to understand how therapists feel about discussing exercise in psychotherapy. Please indicate, in order of importance, up to three reasons why you do or do not ever discuss exercise with your clients.

1)

2)

3)

14) How regularly do you yourself exercise?

(circle one)

1 More than three times per week

2 Two or three times per week

3 Once per week

4 Less than once per week

5 Less than once per month

6 Never

15) What type(s) of exercise do you regularly do?

If there is anything else you could tell us that might help in understanding how you feel about the issues raised in this questionnaire, please comment on the back of this sheet.

THANK YOU VERY MUCH FOR YOUR COOPERATION. If YOu wish to receive results of this study, please enter your name and address on the enclosed label, which will be separated from your questionnaire upon receipt in order to protect the confidentiality of your responses. 


\section{BIBLIOGRAPHY}

American College of Sports Medicine. (1980). Guidelines for graded exercise testing and exercise prescription (2nd ed.). Philadelphia: Lea \& Feabiger.

American Psychological Association Task Force on Health Research. (1976). Contributions of psychology to health research. American Psychologist, 31, 263-274.

Bahrke, M. S., \& Morgan, W. P. (1978). Anxiety reduction following exercise and meditation. Cognitive Therapy

Barrow, J. C., English, T. \& Pinkerton, R. S. (1987). Physical fitness training: Benefits for professional psychologists? Professional Psychology: Research and

Belloc, N., \& Breslow, L. (1972). Relationships of physical health status and health practices. Preventive Medicine, 1, 409-421.

Ben-Shlomo, L. S., \& Short, M. A. (1983). The effects of physical exercise of self-attitudes. Occupational Therapy in Mental Health, $\underline{3}, 11-28$.

Blumenthal, J. A., Williams, R. S., Needles, T. L. \& Wallace, A. G. (1982). Psychological changes accompany aerobic exercise in healthy middle-aged adults. Psychosomatic Medicine, 44, 529-536.

Boutcher, S. H. \& Landers, D. M. (1988). The effects of vigorous exercise on anxiety, heart rate, and alpha activity of runners and nonrunners. Psychophysiology, 25, 696-702.

Brown, D. R. (1986). Exercise and sport as elements in therapy. The Clinical Psychologist, 39, 71-74.

Burks, R., \& Keeley, S. (1989). Exercise and diet therapy: Psychotherapists' beliefs and practices. Professional Psychology: Research and practice, 20, 62-64.

Cooper, K. (1970). The new aerobics. New York: Bantam Books. 
Dishman, R. K. (1986). Mental Health. In V. Seefeldt (Ed.), Physical activity and well-being (pp. 303$342)$. Reston, VA: AAHPERD.

Doyne, E. J., Chambless, D. L., \& Beutler, L. E. (1983). Aerobic exercise as a treatment for depression in women. Behavior Therapy, 14, 434-440.

Eaker, J. N. (1972). On some elementary philosophical problems of psychology. American Psychologist, 27,

Folkins, C. H. (1976). Effects of physical training on mood. Journal of clinical psychology, 32, 385-388.

Folkins, C. H., Lynch, S., \& Gardner, M. (1972). Psychological fitness as a function of physical fitness. Archives of Physical Medicine and Rehabilitation, 53, 503-508.

Folkins, C. H., \& Sime, W. E. (1981). Physical fitness training and mental health. American Psychologist, 36, 373-389.

Frank, J. (1976). Restoration of morale and behavior change. In A. Burton (Ed.), What makes behavior change possible? (pp. 73-95). New York: Bruner/Mazel.

Fremont, J., \& Craighead, L. W. (1987). Aerobic exercise and cognitive therapy in the treatment of dysphoric moods. Cognitive Therapy and Research, 11, 241-251.

Greist, J. H., Klein, J. H., Eischens, R. R., Faris, J. W. , Gurman, A. S., \& Morgan, W. P. (1978). Running through your mind. Journal of Psychosomatic Research, 22, 259-294.

Greist, J. H., Klein, J. H., Eischens, R. R., Faris, J. W., Gurman, A. S., \& Morgan, W. P. (1979). Running as a treatment of depression. Comprehensive Psychiatry, 20, 41-54.

Halgin, R. P., \& McEntee, D. J. (in press). Countertransference dilemmas in integrative psychotherapy. In G. Stricker \& J. Gold (Eds.), Comprehensive Handbook of Psychotherapy Integration. New York: Plenum. 
Holmes, D. S., \& Roth, D. L. (1988). Effects of aerobic exercise training and relaxation training on cardiovascular activity during psychological stress. Journal of Psychosomatic Research, 32, 469-474.

Hughes, J. R. (1984). Psychological effects of habitual aerobic exercise: A critical review. Preventive Medicine, 13, 66-78.

Kavanaugh, T., Shepherd, R. J., Tuck, J. A., \& Qureshi, S. (1977). Depression following' myocardial infarction: the effect of distance running. Annals of the New York Academy of Sciences, 301, 1029-1038.

Klein, M. H., Greist, J. H., Gurman, A. S., Neimeyer, R. A., Lesser, D. P., Bushneil, N. J.\&\& Smith, R. E. (1985). A comparative outcome study of group psychotherapy vs. exercise treatments for depression. International Journal of Mental Health, 13, 148-177.

Layman, E. M. (1974). Psychological effects of physical activity. In J. H. Wilmore (Ed.), Exercise and Sports Sciences Reviews. New York: Academic Press.

Lichtman, S., \& Poser, E. G. (1983). The effects of exercise on mood and cognitive functioning. Journal of Psychosomatic Research, 27, 43-52.

Lobitz, W. C. , Brammell, H. L. , Stoll, S., \& Niccoll, A. (1983). Physical exercise and anxiety management training for cardiac stress management in a nonpatient population. Journal of Cardiac Rehabilitation, $\underline{3}, 683-688$.

Lobstein, D. D., Mosbacher, B. J., \& Ismail, A. H. (1983). Depression as a powerful discriminator between physically active and sedentary middle-aged men. Journal of Psychosomatic Research, 27, 69-76.

Morgan, W. P. (1979). Anxiety reduction following acute physical activity. Psychiatric Annals, 9, 141-147.

Muller, B., \& Armstrong, H. E. (1975). A further note on the "running treatment" for anxiety. Psychotherapy: Theory, Research and practice, 12, 385-387.

orwin, A. (1974). Treatment of a situational phobia a case for running. British Journal of Psychiatry, 125, 95-98. 
Pauly, J. T., Palmer, J. A., Wright, C. C., \& Pfeiffer, G. J. (1982). The effect of a' 14 -week employee fitness program on selected physiological and psychological parameters. Journal of occupational
Medicine, 24, 457-463.

Plante, T. G. \& \&odin, J. (1990). Physical fitness and enhanced psychological health. Current Psychology: Research and Reviews, 9, 3-24.

Raglin, J. S., \& Morgan, W. P. (1987). Influence of exercise and quiet rest on state anxiety and blood pressure. Medicine and science in sports and Exercise, $\underline{19}, 456-463$.

Royak-Schaler, R., \& Feldman, R. H. (1984). Health behaviors of psychotherapists. Journal of Clinical Psychology, 40, 705-710.

Sachs, M. L. (1982): Exercise and running: Effects on anxiety, depression, and psychology. Humanistic Education and Development, 21, 51-57.

Schwartz, G. E., Davidson, R. J., \& Coleman, D. (1978). Patterning of cognitive and somatic processes in the self-regulation of anxiety: Effects of meditation versus exercise. Psychosomatic Medicine, 40, 321-328.

Scott, M. G. (1960). The contributions of physical activity to psychological development. Research Quarterly, 31, 307-320.

Sonstroem, R. J. (1984). Exercise and self-esteem. Exercise and Sports Science Review, 12, 123-155.

Stachnik, T. J. (1980). Priorities for psychology in medical education and health care delivery. American Psychologist, 35, 8-15.

Taylor, C. B., Sallis, J. F., \& Needle, R. (1985). The relation of physical activity and exercise to mental health. Public Health Reports, 100, 195-202.

Thoreson, C. E., \& Eagleston, J. R. (1985) . Counseling for health. Counseling Psychologist, 13, 15-87.

Trujillo, C: M. (1983). The effect of weight training and running exercise intervention programs on the self-esteem of college women. International Journal of Sport Psychology, 14, 162-173. 

He

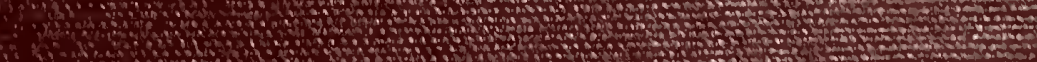

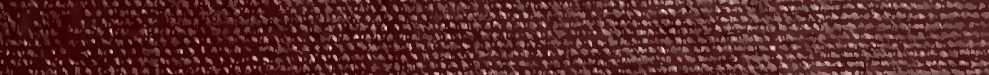

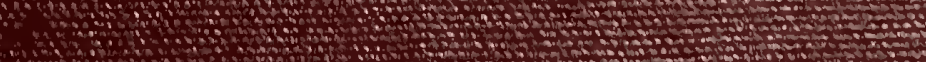
S. 1 (n)

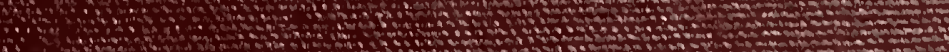

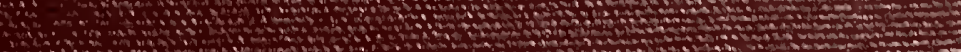

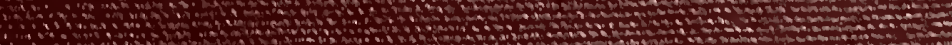

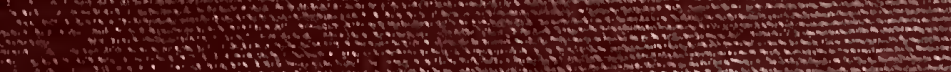

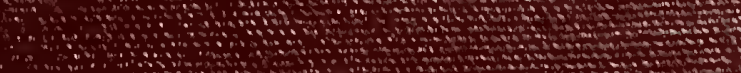

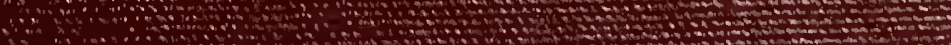

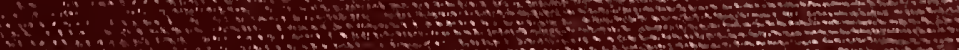
a

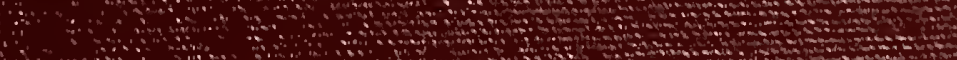

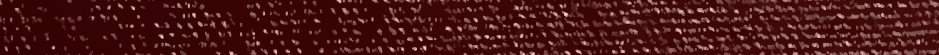

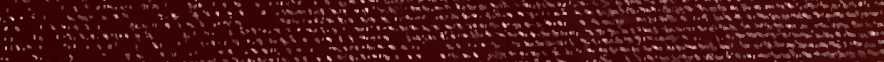

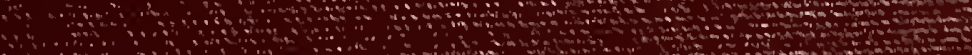

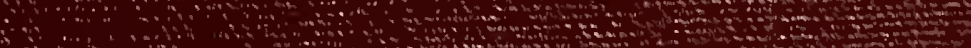
…

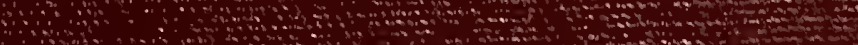
$\therefore \therefore$ a $\because \because 3$ a

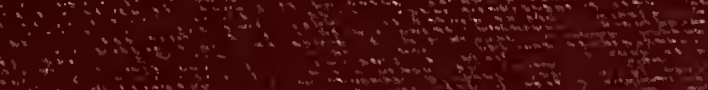

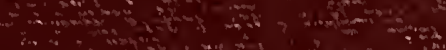

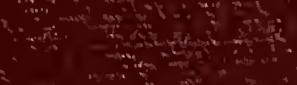

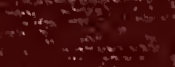

